\title{
A prospective study of indications and maternal outcome in case of emergency obstetric hysterectomy in a tertiary care hospital of Gujarat, India
}

\author{
Mahima Jain*, Devanshi Dave \\ Department of Obstetrics and Gynecology, BJ Medical College, Ahmedabad, Gujarat, India
}

Received: 09 January 2019

Accepted: 05 February 2019

*Correspondence:

Dr. Mahima Jain,

E-mail: drmahimajain@yahoo.co.in

Copyright: ( $)$ the author(s), publisher and licensee Medip Academy. This is an open-access article distributed under the terms of the Creative Commons Attribution Non-Commercial License, which permits unrestricted non-commercial use, distribution, and reproduction in any medium, provided the original work is properly cited.

\begin{abstract}
Background: Obstetric hysterectomy was developed as a heroic operation arising out of necessity to control postpartum haemorrhage thereby reducing maternal mortality. The objectives of this study are to examine the incidence, indications, outcomes and complications of obstetric hysterectomy in a tertiary care hospital. It also aims to study the changing trends in incidence and indications in present day obstetric practice.

Methods: This is a one-year study including 31 cases of obstetric hysterectomy performed in the Department of Obstetrics and Gynecology in a tertiary care hospital of Gujarat. Each case is analyzed, computed and tabulated as per standard proforma including clinical assessment, questionnaire, examination and investigations.

Results: In present study 68\% cases were in 21-30 years which is peak reproductive age. 55\% patients were from rural areas and $52 \%$ cases were having three or more parity. The incidence of obstetric hysterectomy is $0.432 \%$ in both vaginal and cesarean deliveries i.e. 1 in 231 deliveries. Major indication for obstetric hysterectomy is morbidly adherent placenta $32 \%$ followed by atonic PPH $25.8 \%$ and ante partum hemorrhage in $22.58 \%$ due to increase in rate of cesarean sections. Most common complication is DIC and maternal mortality in around $16.12 \%$.

Conclusions: Obstetric hysterectomy is still a lifesaving surgery in modern day obstetrics. Quick decision for obstetric hysterectomy reduces maternal morbidity and mortality. Most of the morbidity is attributable to its indication and underlying disorder rather than the procedure itself.
\end{abstract}

Keywords: Emergency obstetric hysterectomy, Indications, Maternal outcome

\section{INTRODUCTION}

Obstetric hysterectomy was developed as a heroic operation arising out of necessity to control postpartum hemorrhage thereby reducing maternal mortality. It is a last resort in management of life threatening obstetric hemorrhage when all conservative measures have failed to achieve hemostasis. In 1871 Eduardo Porro of Milan succeeded in performing elective hysterectomy after a cesarean section on a 25 -year-old primigravid dwarf in which other and infant survived after a stormy 40 days postoperative courses. He published this case in 1876 in great detail. This operation was then referred as Porro's operation. $^{1,2}$

The commonest indication for emergency obstetric hysterectomy which is cited in literature is postpartum hemorrhage due to uterine rupture and uterine atony. ${ }^{3}$ However due to increase in number of cesarean deliveries over the past two decades, placenta accreta has emerged as a common indication for this operation in developed countries. $^{4}$ Worldwide reports revealed striking 
differences among prevalence rate of obstetric hysterectomy ranging from 1:361 to 1:3000 deliveries depending upon inherent characteristics of concerned obstetric population and standards of available maternity, family planning services and their utilizations. ${ }^{5,6}$

The objectives of this study are to examine the incidence, indications, outcomes and complications of obstetric hysterectomy in our tertiary care hospital and to compare our results with results in published literature.

This study aims to help highlight the lack of availability and utilization of antenatal services, identify avoidable factors and stress the need to organize healthcare services, which will help to improve maternal and the fetal outcome. The aims and objectives of the present study are to know the incidence, indications of obstetrics hysterectomy, to study maternal outcome in relation to morbidity and mortality, and to know the changing trends in incidence and indications of obstetric hysterectomy in present day obstetric practice.

\section{METHODS}

This one-year study includes 31 cases of obstetric hysterectomy performed in the department of Obstetrics and Gynecology in a tertiary care hospital of Gujarat. All patients in this study were delivered inside or outside our hospital and referred for further management.

Each case was analyzed computed and tabulated as per standard proforma which included clinical assessment, questionnaire, examination and investigation. The study hypothesis included to assess indications and maternal outcome in all aspects including causes, mode of delivery in patient referred to or directly approaching hospital, presenting complaints and other high-risk factors.

\section{Inclusion criteria}

- All patients who undergo obstetric hysterectomy within our institute or referred to our hospital after surgery for further management.

The methods and drugs used for the management is also studied. Microsoft excel work sheet and IBM software 22.0 is used for data analysis. $\mathrm{P}$ value $<0.005$ is considered statistically significant.

\section{RESULTS}

In Table 1, 68\% cases belong to 21-30 years age group, $55 \%$ patients are from rural area since ours is a referral centre and stresses the need for adequate health facilities in nearby areas. $52 \%$ cases underwent obstetric hysterectomy with $>=3$ parity.

With increasing parity there is increase in incidence of obstetric hysterectomy as the chances for atonic PPH, placenta previa and sometimes rupture uterus increase.
Surgeon prefer to go for obstetric hysterectomy in this group as child bearing is completed.

Table 1: Distribution of cases as per age, residence, parity.

\begin{tabular}{|l|l|l|}
\hline $\begin{array}{l}\text { Parameters } \\
\text { Age (years) }\end{array}$ & No. of cases, $\mathbf{N}=31$ & $\%$ \\
\hline$<20$ & 0 & 0 \\
\hline $21-25$ & 7 & 22 \\
\hline $26-30$ & 14 & 46 \\
\hline $31-35$ & 09 & 29 \\
\hline $36-40$ & 1 & 3 \\
\hline Residence & & \\
\hline Rural & 17 & 55 \\
\hline Urban & 14 & 45 \\
\hline Parity & & \\
\hline 1 & 1 & 3 \\
\hline 2 & 13 & 45 \\
\hline 3 & 8 & 24 \\
\hline 4 & 7 & 22 \\
\hline$\geq 5$ & 2 & 4 \\
\hline
\end{tabular}

In Table 2, the study showed the incidence of $0.432 \%$ i.e. 1 in 231 total deliveries.

It also shows the increasing incidence since cases of morbidly adherent placenta has risen due to increase in cesarean deliveries.

Table 2: Incidence of Obstetric hysterectomy in our institute (both vaginal and cesarean deliveries).

\begin{tabular}{|l|l|l|l|}
\hline Year & $\begin{array}{l}\text { Total no. of } \\
\text { deliveries }\end{array}$ & $\begin{array}{l}\text { Total no. of obstetric } \\
\text { hysterectomy }\end{array}$ & $\%$ \\
\hline 2016 & 8074 & 27 & 0.334 \\
\hline 2017 & 7294 & 30 & 0.411 \\
\hline 2018 & 7165 & 31 & 0.432 \\
\hline
\end{tabular}

In Table 3, in present study major indication for obstetric hysterectomy is morbidly adherent placenta followed by atonic PPH and antepartum haemorrhage. Due to increase rate of cesarean sections this indication has evolved over years to be a major indication.

Table 3: Indications of obstetric hysterectomy.

\begin{tabular}{|l|l|l|}
\hline Indication & No. of cases, N=31 & $\%$ \\
\hline Rupture uterus & 05 & 16.12 \\
\hline Atonic PPH & 08 & 25.8 \\
\hline $\begin{array}{l}\text { Morbidly adherent } \\
\text { placenta }\end{array}$ & 10 & 32.2 \\
\hline Traumatic PPH & 01 & 3.22 \\
\hline Antepartum Hemorrhage & 07 & 22.5 \\
\hline
\end{tabular}

In Table 4, various methods used to control hemorrhage failed in such cases hence decision for obstetric hysterectomy done to save the life of patient. Due to 
increase rate of cesarean sections this indication has evolved over years to be a major indication.

Table 4: Intervention done to arrest haemorrhage pre-hysterectomy.

\begin{tabular}{|l|l|l|}
\hline Intervention & No. of case, N=31 & $\%$ \\
\hline Uterine packing & 15 & 48 \\
\hline Uterine artery ligation & 14 & 46 \\
\hline Internal iliac artery ligation & 01 & 3 \\
\hline Uterine artery embolization & 1 & 3 \\
\hline
\end{tabular}

In Table 5, the most common complication in DIC mainly due to $\mathrm{PIH}$, haemorrhage and jaundice associated in such patients. Bladder injury is seen in $13 \%$ cases as majority cases are of previous cesarean section with adherent placenta at scar site.

Apart from the injuries other complications are not directly due to the surgery i.e. obstetric hysterectomy itself but due to co morbid conditions in the patients like pre-eclampsia, jaundice, haemorrhagic shock etc.

Table 5: Morbidity and mortality associated with emergency obstetric hysterectomy.

\begin{tabular}{|c|c|c|}
\hline Complication & $\begin{array}{l}\text { No. of } \\
\text { cases, } \\
\mathrm{N}=\mathbf{3 1}\end{array}$ & $\%$ \\
\hline Bladder injury & 4 & 13 \\
\hline DIC & 9 & 29 \\
\hline Acute renal failure & 3 & 10 \\
\hline Acute respiratory distress syndrome & 3 & 10 \\
\hline Septicemia & 3 & 10 \\
\hline Wound gap & 2 & 6 \\
\hline Paralytic ileus & 1 & 3 \\
\hline Burst abdomen & 1 & 3 \\
\hline Maternal mortality & 5 & 16 \\
\hline
\end{tabular}

Maternal Mortality rate is $16.12 \%$ as our hospital is tertiary care hospital majority are referred from the hospitals in condition of shock, DIC, gross intraperitoneal haemorrhage and in critically ill condition requiring ICU facility.

So even after lifesaving surgery such as obstetric hysterectomy it was difficult to revert the patient as they are already in state of irreversible complications.

Cause of mortality was irreversible haemorrhagic shock in these cases, DIC with ARF in one and DIC with septicemia in one case. In Table 6 , if the patient is operated after 4 hours there is increased chance of mortality which is statistically significant. Emergency obstetric hysterectomy is a necessary evil in obstetrics. This is a situation when surgery is in dilemma as in one hand it curtails the further child bearing potential of the women and on the other hand it saves mother in life threatening condition. But decision should be prompt as the study shows that only one mortality recorded if delivery-hysterectomy interval is less than 4 hours as compared to late decision beyond 4 hours.

Table 6: Relation between delivery hysterectomy interval and mortality.

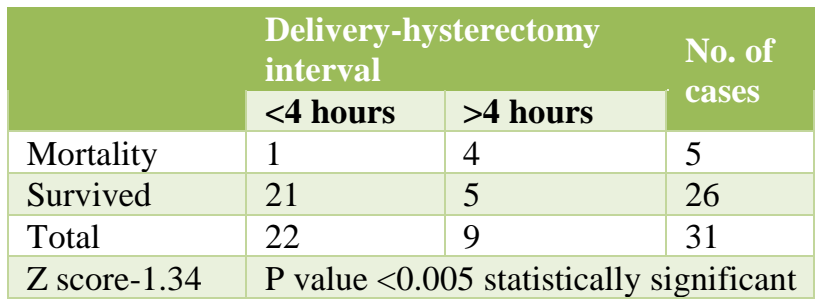

In Table 7, 52\% cases had still birth. Out of 8 babies admitted in NICU, 3 died hence perinatal mortality rate in present study is $37.5 \%$.

Table 7: Perinatal outcome in case of obstetric hysterectomy.

\begin{tabular}{|l|l|l|}
\hline Perinatal outcome & No. of case, $\mathbf{N}=31$ & $\%$ \\
\hline Still birth & 16 & 52 \\
\hline Preterm birth & 7 & 22 \\
\hline Full term birth & 8 & 26 \\
\hline
\end{tabular}

\section{DISCUSSION}

The present study found that $68 \%$ patients belong to age group of 21-30 years which is the peak reproductive age which is similar to that observed in Shirodkar D et al,(6) Sharma B et al, Ambika HE et al and RK Praneshwari Devi et al. ${ }^{6-9}$ In Kant Anita et al, 52\% case were in 31-35 years age as this study was done in Escort hospital where most patients belonged to upper middle and high socioeconomic class and preferred late marriage. In present study $52 \%$ case were third gravida and more which indicates that multiparity leads to complications like APH and PPH. ${ }^{10}$ It shows that the incidence of obstetric hysterectomy increases with increase in parity. The incidence of emergency obstetric hysterectomy in the present study is $0.432 \%$ which is higher than that observed in other studies as ours is a tertiary care hospital high risk patient requiring blood products, intensive care facility are frequently referred here. Morbidly adherent placenta is the most common indication of obstetric hysterectomy followed by atonic PPH and rupture uterus which is as observed by Sharma B et al, and RK Praneshwari et al due to increased incidence of cesarean sections in modern day obstetrics. The maternal mortality rate is $16 \%$ in present study which is higher as compared to several studies. ${ }^{7,9}$ This is due to the fact that our hospital is a tertiary care institute receiving referred cases from all over. By the time the patients arrive in our setup they are already in a deplorable condition. It can be concluded that obstetric hysterectomy is still lifesaving surgery in modern day obstetrics. Quick decision for obstetric hysterectomy reduces maternal mortality. Inspite of this life saving surgery sometimes maternal 
death can occur in few cases which can be prevented by good maternal care, active management of third stage of labor, early recognition of complications, timely referred and easy availability of transport and blood transfusion facility. Reduction in primary cesarean section rate will be helpful to reduce its devastating complication in future pregnancy like rupture uterus and morbidly adherent placenta and ultimately reduces the need of obstetric hysterectomy.

\section{CONCLUSION}

Thus, this will be helpful to reduce maternal mortality and morbidity in long run. Most of the morbidities are attributable to its indications and underlying disorder rather than the procedure itself.

Funding: No funding sources

Conflict of interest: None declared

Ethical approval: The study was approved by the Institutional Ethics Committee

\section{REFERENCES}

1. Earhart AD. The Porro Procedure steps toward decreasing post cesarean mortality. Primcare update OBGYN. 2003;10(3):120-3

2. Park RC, Duff WP, Role of cesarean hysterectomy in modern obstetric practice. Clin. Obstet Gynecol 1980;23(2):601-20.

3. Zelop CM, Harlow BL, Frigoletto FD, Safon LE, Salbman Dh Emerging peripartum hysterectomy AM J Obstet Gynecol. 1993;168(5):1443-8.
4. Najni RS, Cesarean and post-partum hysterectomy-a study from Lahore. J. Coll Physicians Surg Pak. 1994;4:120-5.

5. Gupta S, Hooker J, Bayron J1, Gibson JRM, Obstetric hysterectomy J. Obstet Gynecol.1994 14(3):159-61.

6. Shirodker SD, Pandey A, Yadav S. Emergency obstetric hysterectomy: review at a tertiary care hospital Int J Reprod Contracept Obstet Gynecol. 2016;5(11):3811-4.

7. Sharma B, Saxena N, Gupta V. A retrospective study of emergency obstetric hysterectomy in a tertiary care center for a period of 5 years. Int $\mathrm{J}$ Reprod. Contracept Obstet Gynecol 2016;5(11):3778-1.

8. Ambika HE, Swathi Bhat, Lepakshi BG, Savitha CS, A clinical review of emergency obstetric hysterectomy. Indian $\mathbf{J}$ Obstet Gynecol Res 2017;4(4):424-6.

9. Praneshwari Devi RK, Singh NN, Singh D. Emergency obstetric hystrectomy. J Obstet Gynaecol India. 2004;54:343-5.

10. Kant A, Wadhwani K, Emergency Obstetric hysterectomy. J Obstet Gynecol India. 2005;55(2):132-4.

Cite this article as: Jain M, Dave D. A prospective study of indications and maternal outcome in case of emergency obstetric hysterectomy in a tertiary care hospital of Gujarat, India. Int J Reprod Contracept Obstet Gynecol 2019;8:912-5. 